\title{
Albert Camus contemporain, éd. Dolorès Lyotard
}

\section{Paola Perazzolo}

\section{(2) OpenEdition}

\section{Journals}

\section{Edizione digitale}

URL: http://journals.openedition.org/studifrancesi/6415

DOI: 10.4000/studifrancesi.6415

ISSN: 2427-5856

\section{Editore}

Rosenberg \& Sellier

\section{Edizione cartacea}

Data di pubblicazione: 1 novembre 2010

Paginazione: $584-585$

ISSN: 0039-2944

\section{Notizia bibliografica digitale}

Paola Perazzolo, «Albert Camus contemporain, éd. Dolorès Lyotard», Studi Francesi [Online], 162 (LIV

III) | 2010, online dal 30 novembre 2015, consultato il 15 janvier 2021. URL: http://

journals.openedition.org/studifrancesi/6415 ; DOl: https://doi.org/10.4000/studifrancesi.6415

Questo documento è stato generato automaticamente il 15 janvier 2021.

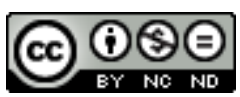

Studi Francesi è distribuita con Licenza Creative Commons Attribuzione - Non commerciale - Non opere derivate 4.0 Internazionale. 


\title{
Albert Camus contemporain, éd. Dolorès Lyotard
}

\author{
Paola Perazzolo
}

\section{NOTIZIA}

Albert Camus contemporain, éd. Dolorès LYOTARD, Villeneuve d'Ascq, Presses

Universitaires du Septentrion, 2009, pp. 218.

1 Pubblicazione parziale delle comunicazioni presentate nel corso di un convegno del 2007, il volume evidenzia l'attualità dell'opera di un A. che affermava provocatoriamente «Je ne suis pas moderne» e il cui «classicisme tragique [...] donnait alors le vrai ton, pour beaucoup inentendu, de notre condition pérenne comme de notre modernité après Auschwitz» (p.11). Se in molti contributi vengono sapientemente evidenziati collegamenti e differenze tra poesia, teatro, romanzo e essais, un'attenzione maggiore viene concessa ai controversi L'Homme révolté e Le Premier homme, due testi particolarmente adeguati alla rilettura contemporanea argomento del volume: «Il en va, si intimement, de la survivance intense, incomparable, de ces œuvres dont l'étonnante anticipation rétrospective, dont le bouleversant contretemps posthume ne cessent de nous atteindre, d'irriguer notre idée du vivre ensemble» (p.13). Ne Le Dernier Camus et la Méditerranée (pp. 15-28), David R. ELLISON si concentra sugli scritti degli anni '50 per evidenziare la presenza di un immaginario costruito a partire dall'elemento sociale e politico ma sotteso da una «pensée du Midi» su cui si sofferma anche Raymond GAY-CROSIER in De l'homo faber à l'homo ludens: défense et illustration de la pensée de midi (pp. 29-44).

2 Alcuni contributi esaminano i rapporti tra l'A. e altri pensatori più o meno contemporanei: Philippe SАВот (Les Mésaventures de la dialectique. Camus critique de Kojève dans "L'Homme révolté", pp. 45-60) mostra come la portata critica dell'opera non possa essere disgiunta dal contesto di pubblicazione (del 1947 sono Humanisme et Terreur di Merleau-Ponty e l'edizione dei corsi di Kojève sulla Fenomenologia dello spirito) in quanto 
l'umanesimo camusiano e il concetto di rivolta misurata si pongono come superamento della negatività e della praxis storica così come dell'idea kojeviana di una salvezza secolarizzata; Gérard FARASSE (Ponge et Camus: un dialogue désaccordé, pp. 103-120) evoca insospettate influenze e affinità tra figure apparentemente opposte quali quelle citate; Maurice WEYEMBERGH (La Tentation du "tout est permis". Camus entre "détour" et "retour", pp.61-77) indaga la problematica dell'omicidio-privato e pubblico-e della sua giustificazione alla luce del superamento di un nichilismo di nicciana memoria riscontrabile anche in Dostoievskij. Il riferimento all'autore russo ispira anche Philippe FOREST che, in Albert Camus et l'infanticide (pp. 77-90), mostra la coerenza del pensiero camusiano pervaso dal ricorrere della riflessione sull'assurdità dell'infanticidio, mentre Aliocha WALD LASOWSKI (Éclats tragiques, pp. 91-102) si interroga sul significato della rivolta quale appare nelle prime opere di Camus e Sartre.

3 Si concentra sulla produzione ultima Pierre-Louis REY, che in Les Strates de la mémoire dans "Le Premier homme" (pp.121-130) esamina l'opera citata come testo di memoria volontaria-egotista e collettiva - e di ricerca delle diverse stratificazioni dell'io. Il lungo saggio di Dolorès LYOTARD (La Prose du Jour, pp. 131-174) ripercorre la produzione dell'A. per sottolineare come la creazione tenda ad essere «prose du monde» e ad impadronirsi de «l'événement du Jour sans pourtant se contenter de l'anecdote immédiate qui en motive mais aussi en suture le sens» (p.133). Termina il volume Gérald SFEZ, (La Voix incendiée, pp. 175-218) che si interroga sul movimento della rivolta ne L'Homme révolté, un testo che «dresse l'inventaire philosophique des légitimités et des égarements de la révolte» (p. 175). 